\title{
LA DEDICATORIA DE LA FILOSOFÍA CORTESANA DE ALONSO DE BARROS A MATEO VÁZQUEZ DE LECCA ${ }^{1}$
}

\author{
Ernesto Lucero \\ (Universidad de Jaén)
}

\section{RESUMEN}

Alonso de Barros concibió la escritura como un servicio cortesano. En este trabajo analizamos la dedicatoria de su Filosofía cortesana a Mateo Vázquez de Lecca desde los estudios sobre la Corte, en relación con la historia editorial del texto, basándonos en especial en el reciente descubrimiento de la edición príncipe y apoyándonos en nueva documentación de archivo.

PALABRAS CLAVE: Alonso de Barros, Mateo Vázquez de Lecca, Filosofía cortesana, Dedicatorias, Corte, Patronazgo.

\section{THE DEDICATION TO MATEO VÁZQUEZ DE LECCA IN FILOSOFÍA CORTESANA, BY ALONSO DE BARROS}

\begin{abstract}
Alonso de Barros understood writing as a court service. In this paper, we are going to analyse his dedication of Filosofía cortesana to Mateo Vázquez de Lecca departing from the Court Studies, in relation to the background of the text's publishing house. We are bearing in mind specially the first edition of the text, recently discovered, and taking into account new archival data.
\end{abstract}

KEY WORDS: Alonso de Barros, Mateo Vázquez de Lecca, Filosofía cortesana, Dedications, Court, Patronage system.

${ }^{1}$ Abreviaturas: AGS (Archivo General de Simancas), CCA (Consejo de Cámara de Castilla); AHN (Archivo Histórico Nacional); BNE (Biblioteca Nacional de España); IVDJ (Instituto Valencia de Don Juan). 
Alonso de Barros pertenece a una familia de la nobleza segoviana muy vinculada al servicio de la Monarquía. En 1563, a la muerte de su padre, ayuda de cámara de Carlos $\mathrm{V}$ y aposentador, arranca su prometedora trayectoria en el laberinto cortesano sustituyéndolo en este último oficio, muy necesario entonces por el reciente asentamiento de la Corte en Madrid. Barros, que todavía debía de ser muy joven, permanecerá en ese puesto algo más de cuatro décadas hasta el fin de sus días, pero nunca colmó sus aspiraciones cortesanas. Por eso, cuando considera que las circunstancias le son favorables, se convierte en un asiduo pretensor de oficios reales. Desde principios de la década de los años ochenta, coincidiendo con el periodo hegemónico de la facción castellanista, de la que formaba parte, emite varios memoriales. En ellos pretende hacer valer ante el rey sus años como aposentador y su seguramente discreta participación en la milicia, además de otros pequeños pero valiosos desempeños; lo que nunca esgrime en su favor es lo que aquí lo trae: sus libros. Sin embargo, no cabe duda de que los textos que pasa a letra de molde persiguen agradar a su patrón ${ }^{2}$, manifestar a través de la dedicatoria una actitud de servicio a la que subyace un vínculo quizá aparentemente nimio o trivial, que, sin embargo, puede comportar implicaciones profundas de orden político o religioso entre el escritor y su mecenas, como es el caso.

Alonso de Barros no se prodigó en las prensas madrileñas. Dejando de lado su participación en los textos liminares de obras ajenas, solo publicó dos trabajos: su Filosofía cortesana, de principios de 1587, y los Proverbios morales, ya en 1598. En estas páginas nos vamos a detener en la dedicatoria de la primera, que encomienda a Mateo Vázquez de Lecca, el poderoso secretario de Felipe II.

Este opúsculo titulado Filosofía cortesana consta de un conjunto de instrucciones precisas para adaptar el conocido juego de la oca al ámbito de la Corte, mostrando en los emblemas de un grabado que acompaña a la edición las vicisitudes y obstáculos que debe acometer el pretensor para lograr la merced que ansía. El propio Barros era un experimentado cortesano que comprendía muy bien la situación global por haberla vivido en carne propia casi desde siempre. Sabía que era fácil errar el camino en el laberinto cortesano y que no resultaba sencillo afrontar la frustración. Por eso procura con este libro, en palabras de Liñán de Riaza, «reducir a placer la pesadumbre / de pretensiones que consumen vidas», mientras enseña las técnicas del medro para sobreponerse a Fortuna. Y algo más: también Barros tenía sus anhelos personales, que pasaban por la obtención de otro oficio real mejor retribuido o cuyo cargo pudiera ostentar de manera simultánea con el que ya le pertenecía. De ahí que ofrezca la doctrina que se extrae del libro en beneficio de la república como servicio a su patrón. La naturaleza del texto no podría haber hallado mejor destinatario que Mateo Vázquez, quien —según declara Barros- puede considerarse un lector

${ }^{2}$ Ver Patricia Marín Cepeda, Cervantes y la corte de Felipe II. Escritores en el entorno de Ascanio Colonna (1560-1608) (Madrid: Polifemo, 2015), 37. Es punto de partida inexcusable en lo que concierne a Barros y a su Filosofía cortesana el imprescindible trabajo de José Martínez Millán, "Filosofía cortesana de Alonso de Barros (1587)", en Política, religión e inquisición en la España moderna: Homenaje a Joaquín Pérez. Villanueva, ed. P. Fernández Albaladejo, J. Martínez Millán y V. Pinto Crespo (Madrid: Universidad Autónoma de Madrid, 1996), 461-482. 
cualificado que «lo entenderá mejor que otros» en atención a su posición social y política y a su trayectoria vital. Así, cuando la Filosofía cortesana vio la luz en el taller que regentaba la viuda de Alonso Gómez ${ }^{3}$ iba «dirigida a Mateo Vázquez de Leca, del Consejo de su Majestad, y su secretario, y de la Santa General Inquisición, arcediano de Carmona, y canónigo en la Santa Iglesia de Sevilla», según figuraba en su portada, dando cuenta de todos los cargos de relieve que el personaje ostentaba. En páginas interiores, además, se aludía a los estrechos vínculos que unían al autor y al dedicatario, más allá de la pura relación clientelar, si hemos de creer a Barros:

La Filosofía cortesana, que presento a V. M., es dotrina -según ha parecido a los hombres cuerdos que la han visto- necesaria para que los que por eleción o por necesidad pretenden ser acrecentados sepan los principios, los medios y los fines por do caminan y vienen a parar las pretensiones humanas.

Por esta razón no he podido excusar de ofrecer a V. M. esta tan pequeña obra en las palabras, y tan grande en la sustancia y verdades que en ella hay; y porque el lugar que V. M. tiene, que es de tanta importancia y consideración, y como un centro de los negocios desta Monarquía, lo entenderá mejor que otros, y con el valor de su persona y la antigua grandeza de las casas de Leca y Colona, de donde deciende, la defenderá de los que, no considerando el trabajo que estas cosas cuestan, ni el buen ánimo con que se hacen, aplican el suyo solo para calumniarlas.

El mío ha sido hacer este beneficio a la República y mostrar el grande amor y estimación que tengo de su clara y generosa persona, debajo de cuyo amparo pongo esta obra, como lo está el autor della, que es premio de los mayores que puedo desear de mis trabajos ${ }^{4}$.

Ese mismo año consigue Alonso de Barros un reconocimiento a sus méritos, que lo hacen acreedor de la escribanía mayor de rentas de la merindad de Santo Domingo de Silos, aunque no sin dificultad. Nos consta por un memorial de 1587 que ya en el mes de marzo, unas semanas después de haber obtenido la aprobación para publicar su obra ${ }^{5}$, había reclamado el puesto, pero la concesión quedó en suspenso. Se demorará hasta el mes de septiembre, una vez que se aclaren algunos extremos al rey. Las consultas se refieren a dos aspectos particulares ${ }^{6}$ : por una parte, el puesto solo lo solicita Barros; por otra el oficio llevaba vacante más de una década, desde la muerte de Antonio Vaca de Castro en 1576.

\footnotetext{
${ }^{3}$ Localizamos y demostramos que se trataba de la primera edición de la obra en Ernesto Lucero, "Las ediciones antiguas de la Filosofía cortesana de Alonso de Barros. Una historia del texto", Criticón 127 (2016): 169-195.

${ }^{4}$ Barros, Filosofía cortesana, ed. Trevor J. Dadson (Madrid: Comunidad de Madrid, 1987), 8r-9v.

${ }^{5} \mathrm{La}$ aprobación de Alonso de Ercilla es de 13 de enero. El privilegio, de 9 de febrero. Falta la tasa, que era obligatoria según la rigurosa Pragmática de 1558.

${ }^{6}$ Respuesta del Rey a 26 del mismo mes: «Avíseme cómo ha tanto tiempo que está vaca, y si se me ha consultado otras veces, y si la piden otros». (Su rúbrica). (AHN, Consejos, leg. 4410, fol. 60 [1587]). Este documento es bien conocido desde la transcripción de Cristóbal Pérez Pastor, Bibliografía madrileña III (Madrid: Tip. de la Revista de Archivos, Bibliotecas y Museos, 1891-1907) 331-333, doc. 4. Tan solo hemos actualizado la referencia. Asimismo, hemos localizado la solicitud original en el Archivo de Simancas.
} 
Lo que hay que decir en cumplimiento de lo que V. Majestad mandó responder a esta consulta es questa escribanía de rentas no se ha consultado a V. Majestad antes por no haberla pedido nadie hasta que el dicho Alonso de Barros la pidió, y no se ha entendido que haya otra causa para no haberla pedido otras personas sino no haber tenido noticia della; y después que V. Majestad mandó responder a la dicha consulta, me ha mandado remitir un memorial del contador Juan de la Peña Zorrilla en que suplica a V. Majestad que en consideración de que ha más de 25 años que le sirve, le haga V. Majestad merced della. De Madrid, a 10 de septiembre, 15877.

Aunque existían memorias de oficios vacos, como se sabe, no hemos localizado ninguna que recogiera cualquiera de los que Alonso de Barros solicitó en su dilatado recorrido como pretensor ${ }^{8}$. No son, desde luego, sistemáticas y es más que dudosa su publicidad, por lo que Alonso de Barros se nos presenta como un cortesano bien informado. Por otra parte, la oportuna aparición de este cargo casi de inmediato tras la edición de su didáctico juego llama la atención; que nadie lo pidiera durante tantos años, también, incluso al monarca. Y llamativo -aunque no descartamos que puramente anecdótico- es el lapsus calami del solicitante, quien demanda se le haga «merced de la escribanía mayor de rentas de Santo Domingo de ta Calzada, que está vaca», corrigiendo de inmediato su tenor para sobrescribir entre líneas «Silos»?.

Ante las dificultades que se observan, debe intervenir para inclinar la balanza Juan de la Peña Zorrilla, a quien Barros debía de conocer por su común origen segoviano ${ }^{10}$, pero detrás de cuya mediación, así como de las circunstancias comentadas hace un momento, creemos ver la sombra de Mateo Vázquez, esa «clara y generosa persona».

No queremos decir que la publicación de un libro dedicado al patrón baste para la consecución de una merced tan preciada y escasa como un oficio real. Seguramente Barros se hizo acreedor de ella por un cúmulo de circunstancias mucho más denso y sin duda alcanzó el favor del secretario a través de un servicio más próximo del que nos consta y quizá también más cotidiano y prolongado en el tiempo pues muy a menudo la dependencia cortesana deparaba gratificaciones mucho menos tangibles que este puesto, remunerado con unos nada despreciables 20.021 maravedíes de quitación ${ }^{11}$. En ese sentido debemos interpretar la

\footnotetext{
${ }^{7}$ AHN, Consejos, leg. 4407 (1587), doc. 60.

8 Por ejemplo, AGS, CCA, leg. 518, doc. 42, de esas fechas.

${ }^{9}$ AGS, CCA, leg. 629, doc. 61.

10 Aparece mencionado en entre los encargados de la labor de la plata en el Ingenio de la moneda de Segovia en 1585, según Casto María del Rivero, El Ingenio de la moneda de Segovia (Madrid: Maxtor, 1919), 27. No está de más recordar que Diego del Espinar, cuñado de Alonso de Barros, fue hasta su fallecimiento ensayador de la Casa de la moneda, la antigua, puesto que reclamó para sí nuestro autor en 1583. Véase AHN, Consejos, leg. 4409, fol. 99 (1583). También hemos localizado la solicitud en el Archivo de Simancas, y daremos noticia y detalles en otro lugar.

${ }^{11}$ Recordemos las excusas de los hombres a los que ha servido que anota Diego Gracián (ver Margherita Morreale, "Estudio preliminar" a Lucas Gracián Dantisco, Galateo español [Madrid: CSIC,
} 
proclamación de «grande amor y estimación» a que se refiere el autor y que relacionaremos más tarde con un pequeño manuscrito preservado, precisamente, entre los papeles del secretario.

Hasta aquí hemos tratado de establecer una relación clientelar entre Alonso de Barros y el patrón del partido castellanista a la altura de 1587. Hemos sugerido que se trata de una conexión dilatada en el tiempo y anticipábamos que responde también a ciertas afinidades personales, como su común inclinación al trabajo, propia de la ideología política de esa facción. El resultado de esta proximidad es el medro efectivo del escritor, que obtiene un nuevo oficio real compatible con el cargo que ya ostenta en fechas muy cercanas a la publicación de su exitosa obra, aunque no como consecuencia inmediata y exclusiva de ella. Pero el patronazgo es un camino de ida y vuelta. En las próximas páginas vamos a tratar de perfilar la participación de Alonso de Barros en la construcción de la imagen de Mateo Vázquez desde los paratextos de su libro, dentro de una estrategia mucho más amplia, pero en la que ocupa un lugar importante.

Mateo Vázquez puso en marcha desde principios de los años 80, tras lograr la privanza del rey, la maquinaria propagandística con la que pretende transformar su poder efectivo en consideración social. La historia editorial de la Filosofía cortesana refleja de alguna manera ese afán. La primera edición, además de la invocación en portada, incluía el encomio de Mateo Vázquez que hemos citado por entero, y que ilumina el camino. No sólo se le considera modelo de cortesano hecho a sí mismo, muy en consonancia con la temática del juego creado por Barros, sino que se anuda «el valor de su persona y la antigua grandeza de las casas de Leca y Colona, de donde deciende» ${ }^{12}$. Esta alusión a la raigambre familiar del personaje no tendría nada de particular en otros casos. En el de Mateo Vázquez, se pretende alejar las dudas que siempre ha despertado su bizantino linaje y su admirable nexo con la familia italiana como parte de un proceso mixtificador avalado por las ínfulas nobiliarias del sujeto y puede que también espoleado por su notable declive político hacia 1585, acentuado por la creación de la Junta de Noche ${ }^{13}$. Ese «centro de los negocios de esta Monarquía», como lo presenta Barros, quizá ya no lo es tanto.

La relación con la letra impresa de los nobles en general y de Mateo Vázquez en particular fue casi siempre utilitaria. Se instrumentaliza la literatura como medio de propaganda genealógica susceptible de crear opinión para mantener, en última

1968], 8-9) o las quejas vertidas por Suárez de Figueroa en el discurso 32, "De los que componen libros; y sus mecenas o protectores", de su Plaza universal de todas ciencias y artes (Madrid: Luis Sánchez, 1615).

12 Alonso de Barros, "Dedicatoria a Mateo Vázquez", en Filosofía cortesana, 9r. El conjunto de la dedicatoria es un acto explícito de reconocimiento de un patrón. Repárese en que da por buena la versión oficial del linaje de Mateo Vázquez.

13 Como dice el marqués de Cerralbo «el origen y nacimiento de Mateo Vázquez son tan fantásticos como oscuros» ("El secretario Mateo Vázquez y la genealogía", Revista Hidalguía 3 [1953]: 621-628, 622) y siempre fueron motivo de incesante ataque por parte de sus rivales políticos. No se equivocaba en su intento de asimilar su posición a la de la nobleza tradicional pues cuando esta vuelva a ganar la privanza del rey, la posición de Mateo Vázquez se verá comprometida. 
instancia, la preeminencia social ${ }^{14}$. La literatura se difunde con gran extensión, pero sobre todo, pervive, logra fijar la memoria. Ese es el motivo por el que piensa Carmen Sanz Ayán que se acercan los nuevos linajes a lo escrito, aunque no tenía en mente abolengos dotados de este grado de fantasía cuando expuso sus ideas ${ }^{15}$.

Algunas características de las sucesivas ediciones del texto de Alonso de Barros se nos antojan intentos de ese lavado de cara y obedecen de manera directa o indirecta a la relevancia social y política del dedicatario. La publicación de otra impresión en el mismo año de 1587 se debe al éxito de la príncipe tanto como a la popularidad del juego que toma como punto de partida ${ }^{16}$, pero eso no explica de manera inequívoca el cambio de taller o algunas de las modificaciones que contiene; tampoco que se tirase en castellano una edición en Nápoles al año siguiente. Estas y otras cuestiones podrían esclarecerse - $\mathrm{O}$ no- desde la perspectiva de que la obra constituye un jalón en el proceso de fundación de una estirpe ficticia de nuevo cuño. Por ello, vamos a tratar de aclarar las dudas que propone la historia editorial de la Filosofía cortesana a la luz de las relaciones de autor y dedicatario.

Dentro una estrategia razonable de dar más por menos, la segunda edición de Pedro Madrigal ofrecía mejoras sustanciales a pesar de la reducción del formato del libro: incorporaba un prólogo al lector, un grabado de Fortuna y una ejemplificación del juego entre otros cambios y adiciones de mayor o menor consideración, además

\footnotetext{
${ }^{14}$ Marín Cepeda, Cervantes, 147.

15 Aludimos a la ponencia plenaria que ofreció Carmen Sanz Ayán en el congreso de AISO, titulada "Linajes de papel. La imagen de la nueva nobleza en los paratextos del siglo de oro" (Madrid: Universidad Complutense, julio de 2017, pendiente de publicación). Como es sabido, Mateo Vázquez pensó en ir más allá de las dedicatorias ajenas cuando, en la cúspide de su poder, encarga una información que pretende pasar por la versión oficial de su nobleza con intención de publicarla, aunque nunca llegó a hacerlo. Las averiguaciones se conservan como "Origen y descendencia de la ilustrísima y antigua familia y Casa de Lecca”, en la Biblioteca Nacional de España (Juan Manuel, obispo de Sigüenza, "Lo que supe y entendí, siendo deán de Sevilla, en el particular del secretario Mateo Vázquez de Leca”, BNE, Mss. 9512; véase IVDJ, envío 57, caja 76, paquete 6, fol. 65: «El traslado de mi genealogía va aquí», escribe el secretario de propia mano). Han sido ya demasiados los que se han referido a este asunto, de manera que no insistiremos. Remitimos al marqués de Cerralbo, "El secretario", 621-628; A. W. Lovett, Philip II and Mateo Vázquez de Leca: the Government of Spain (1572-1592) (Genêve: Librairie Droz, 1977); S. Poole, "The Politics of limpieza de sangre: Juan de Ovando and His Circle in the Reign of Philip II", The Americas. A Quarterly Review of Inter-American Cultural History, 55 (1999): 359-389; y, más recientemente, José Luis Gonzalo Sánchez-Molero, "Mateo Vázquez de Leca, un secretario entre libros", Hispania 65, no 221 (2005): 813-846; La "Epístola a Mateo Várquez": historia de una polémica literaria en torno a Cervantes (Alcalá de Henares: Centro de Estudios Cervantinos, 2010) y "Mateo Vázquez de Leca, un secretario entre libros, 2. La biblioteca", Hispania Sacra 66, no 1 (2014): 35-65; Manuel Díaz Gito "Una carta en torno al escudo de armas de Mateo Vázquez de Leca en la Corsica de Calvete de Estrella", Calamus renascens 10 (2009): 53-70 y "Encomio de Mateo Vázquez y heráldica de los Lecca en la 'Corsica' de Calvete de Estrella”, Talía dixit. Revista Interdisciplinar de Retórica e Historiografía 9 (2014): 73-95; y Marín Cepeda, Cervantes, 325-333. Esta recupera con acierto el adjetivo «bizantino» ya empleado por Cerralbo. Ver acerca del interés de Mateo Vázquez por limpiar su sangre el significativo arranque del mencionado trabajo de Poole.

${ }^{16}$ Expusimos algunas ideas en una ponencia pendiente de publicación, titulada "Unas palabras sobre el ocio cortesano: La Filosofía cortesana moralizada y el juego de la oca", Simposio Internacional sobre Caballería y Corte (SICC), Universidad de Jaén, 30 de enero de 2018.
} 
de unos sonetos preliminares de Cervantes y de Liñán de Riaza y de la crucial inclusión del escudo del secretario ${ }^{17}$. La aportación de estos poetas merece unas palabras antes de volver a tratar de la edificación de la imagen de Mateo Vázquez.

Comenzaremos por señalar que la mera presencia de tales escritores en los paratextos resulta aparentemente disonante, pues se aviene con dificultad a la pertenencia de Alonso de Barros al partido castellanista y con la dedicatoria de la Filosofía cortesana a su patrón. En efecto, las conexiones de Miguel de Cervantes con esta facción han sido revisadas por Marín Cepeda, que mantiene que se halla más próximo al bando papista. Figura aquí junto a Liñán, el Lineo de $\mathrm{La}$ Galatea, libro que Cervantes dirige a un conocido ebolista como Ascanio Colonna, pero a quien Mateo Vázquez pretende ganar para la causa de su linaje, de donde se deduce que las facciones - asegura la estudiosa - no son compartimentos estancos: los cortesanos de uno y otro lado establecen relaciones personales y políticas complejas, no siempre unívocas, muchas veces movidos por la necesidad de arrimarse al poder o por cualesquiera otras razones de utilidad política.

Entrando en detalle, siempre hemos pensado que en el cambio de impresor para la segunda edición puede hallarse de fondo la personalidad de Blas de Robles, que los conoce a todos y que ya había posibilitado la citada novela de pastores dos años atrás. Recordemos que este personaje es uno de los tres libreros que financian habitualmente a María Ruiz, viuda de Alonso Gómez, que publica la princeps de la Filosofía cortesana, y que Pedro Madrigal trabaja en exclusiva con él entre 1586 y 1588, justamente ${ }^{18}$. Robles bien pudo promocionar, entre otros, a este soldado poeta apellidado Cervantes con el fin de aproximarlo a los canales de la gracia para favorecerlo. De hecho, Gonzalo Sánchez-Molero no tiene duda de que a partir de un cierto momento el alcalaíno se halla en el propio cenáculo de Mateo Vázquez ${ }^{19}$, apuntando además su eventual intervención en las tertulias de Lobo Lasso de La Vega, también relacionado con Vázquez de Lecca.

Sin embargo, nos parece altamente sugestiva otra posibilidad para enlazar estas vidas, además de la antedicha, y que no la excluye. Nos referimos a los nudos de Antonio de Toledo con todos estos nombres. Por una parte, es amigo del secretario, mientras por otra mantiene correspondencia con Ascanio Colonna entre 1584 y 1588, a quien se ofrece como intermediario en sus relaciones con Vázquez de Lecca ${ }^{20}$.

${ }^{17}$ Son de gran interés las recientes reflexiones sobre la autoría dentro del campo literario, una autoría que se difumina en portada merced a la incorporación del escudo del impresor o del dedicatario. En la primera edición de la Filosofía cortesana, el principio carece de grabado y las letras anuncian a las claras la autoría de Alonso de Barros. La edición de Pedro Madrigal, en cambio, dirige la mirada del lector hacia el blasón de Mateo Vázquez, por lo que se diluyen un tanto los contornos del autor. Puede verse, entre otros, Ignacio García Aguilar, Poesía y edición en el Siglo de Oro (Madrid: Calambur, 2009), 125-188.

18 Ver Juan Delgado Casado, Diccionario de impresores españoles (siglos XV-XVII) (Madrid: Arco/Libros, 1996) y Yolanda Clemente San Román, Tipobibliografía Madrileña. La imprenta en Madrid en el s. XVI (1566-1600) (Kassel: Reichenberger, 1998), 3 vols.

19 Gonzalo Sánchez-Molero, "La biblioteca", 249: «parece evidente que Cervantes se prestó durante un tiempo a ser uno de los auxiliares en los proyectos culturales del secretario».

${ }^{20}$ Marín Cepeda, Cervantes, 110-114; 415. 
Compañero de cautiverio de Cervantes, fue seguramente él, y no Rodrigo Cervantes, el que trajo de Argel en 1577 la «Epístola a Mateo Vázquez» ${ }^{21}$. El futuro conde de Alba de Liste participaba del gusto por la escritura y solía visitar estas academias. Le conocemos un poema sobre el menosprecio de corte que preservó Mateo Vázquez entre los «Diversos de curiosidad» de su escritorio, que contenían también la citada epístola cervantina y un texto de Alonso de Barros titulado «Discurso y difinición del privado», que ya hemos anunciado y que mencionaremos de nuevo en seguida. Nos interesa además que el «turquete», como lo llamaban, había tomado parte en el socorro de Malta y había viajado a Portugal con Felipe II, igual que nuestro autor. Por lo demás, las amistades literarias son caprichosas. Se puede discutir si Cervantes se hallaba o no en los encuentros organizados por Lobo pero, del mismo modo que sabemos gracias a Alexandre Roquain que hubo alguna proximidad inesperada entre Mateo Vázquez y Lope de Vega ${ }^{22}$, nada parece oponerse a que existiera algún tipo de relación personal, de amistad, entre el autor de la Filosofía cortesana y los poetas que elogian la obra en los textos liminares, sino todo lo contrario ${ }^{23}$.

A propósito del segundo asunto planteado, la incorporación del escudo en la segunda edición del librito que venimos comentando, debemos detenernos en dos cuestiones de gran interés: la primera afecta a un replanteamiento de la autoría del pequeño tratado; la segunda se refiere a la estrategia propagandística del dedicatario. La inserción del grabado del escudo de armas de Mateo Vázquez en la portada es, sin duda, la remodelación más llamativa de la edición de Pedro Madrigal. Es punto menos que imposible que una decisión editorial de esa trascendencia dependiera del propietario del taller de imprenta o del autor sin contar no ya con la simple anuencia del secretario, sino con su verdadero auspicio. En este sentido, cuando todavía no habíamos ofrecido noticia de la existencia de una edición anterior a esta, descrita por primera vez por Edward M. Wilson ${ }^{24}$, algunas voces perspicaces pusieron de manifiesto una posible intervención de mayor o menor entidad del círculo más

${ }^{21}$ Se trata de una sólida y sugestiva hipótesis propuesta por Gonzalo Sánchez-Molero, "La Epístola”, 215 y ss.

${ }^{22} \mathrm{El}$ primero le regaló a este un volumen facticio compuesto por dos títulos de Girolamo Muzio. Tenemos noticia de este asunto por Gonzalo Sánchez-Molero, "La Epístola”. Lope participó en los paratextos de los Proverbios morales de Alonso de Barros, de los que nos ocupamos en otro lugar. Aunque nadie lo ha cuestionado abiertamente desde que Martínez Millán lo adscribió al partido castellanista, llama la atención la interpretación de la religiosidad de Alonso de Barros que Cavillac observa en las lecturas del inventario de su biblioteca, que lo aproximan, a su juicio, a una forma de religiosidad interior que no se corresponde con su militancia. Michel Cavillac, "Libros, lecturas e ideario de Alonso de Barros, prologuista de Guzmán de Alfarache (1599)", Bulletin Hispanique 100 (1998): 69-94. El listado, en efecto, ofrece algunas dudas, si bien hay motivos más que suficientes para considerarlo cliente de la red de Mateo Vázquez en los años que estamos aquí considerando.

${ }^{23}$ Hemos conocido recientemente que un pariente de Alonso de Barros, Cristóbal, comisionó a Cervantes en 1593 en tierras andaluzas. Ver José Cabello Núñez, "Nuevos documentos para la biografía de Miguel de Cervantes Saavedra, un comisario real de abastos en los antiguos Reinos de Jaén y Sevilla (1592-1593)", Anales cervantinos 48 (2016): 13-51.

${ }^{24}$ Edward M. Wilson, "A Cervantes item from Emmanuel Collage Library: Barros's Filosofía cortesana, 1587", Transactions of the Cambridge Bibliographical Society 4 (1968): 363-371; y Lucero, "Las ediciones antiguas". 
próximo a Vázquez de Lecca o su misma ideación de la Filosofía cortesana. El propio Barros admite en la dedicatoria que nos ocupa que ha dado a leer el texto a «algunos hombres cuerdos». Es de suponer que quizá comentaran alguna línea o sugirieran alguna modificación. Por este camino, alguno podría pensar que dicha participación fuese tan significativa que nos halláramos, incluso, ante una obra colectiva, al menos en cierto sentido, surgida del hontanar de una academia literaria o cenáculo alrededor de este patrón y eventual mecenas, donde podríamos encontrar a nuestro Alonso de Barros. Él, criado del Rey, asumiría la firma por ser la personalidad más oportuna. Martínez Millán ha reflexionado en esta línea y sostiene que Cervantes pudo obtener la comisión de ese año como merced por su asistencia en el proyecto de la Filosofía cortesana, a su juicio más amplia que el solo soneto de los preliminares:

Aunque dicho juego tiene la autoría de Alonso de Barros, resulta muy probable que fuera comentado e, incluso, anotado por algunos de sus amigos del grupo que formaban estos contingentes escritores entre los que se encontraba Cervantes; así se colige de los sonetos que preceden al juego cuando fue publicado, entre los que se encuentra un soneto del propio Cervantes ${ }^{25}$.

Para Gonzalo Sánchez-Molero, la crítica del juego y la valoración de la ética del trabajo que vertebran la obra podrían sugerir esa intervención o dirección de Vázquez de Lecca y sus adláteres ${ }^{26}$. De ser así, en todo caso, no se puede determinar el alcance de dicha participación plural ni concretar los casos específicos ni su incidencia real en la versión definitiva del tablero o del texto, que bien parecen obra de una sola mano, ni tampoco si esa injerencia debe mirar a la edición primera o simplemente a los cambios y añadidos de la segunda. Porque lo cierto es que ahora contamos con la príncipe, de la que podemos afirmar que ninguno de esos señalados partícipes ha dejado otra huella explícita, pero indeterminada, que la referencia de Barros a esos «hombres cuerdos» que han visto lo que ha escrito.

La autoría de Barros, a nuestro entender, está fuera de duda en la concepción de su tiempo, no ya porque solicita la aprobación y el privilegio o porque se le atribuya en todo momento sin ambages la creación íntegra de la Filosofía cortesana, sino porque hemos detectado entre los pocos motivos que figuran en los lemas alguna referencia menor a su tierra que alguien foráneo quizá no tendría presente y porque pensamos que en el origen de ciertos emblemas, las lecturas e incluso la biografía de Barros se manifiestan espontáneamente y, por el contrario, no hallamos elementos discordantes. Además, Segovia nos parece de trascendental importancia en la génesis de la emblemática española, según hemos comentado en otro lugar ${ }^{27}$. Cosa diferente es que se pueda negar su voluntaria implicación en una estrategia más

${ }^{25}$ Martínez Millán, "Cervantes y las facciones cortesanas de su tiempo (1547-1616)", Colecciones cervantinas (Madrid: Ministerio de Educación, Cultura y Deporte, Subdirección General de Documentación y Publicaciones, 2016), 98.

${ }^{26}$ Gonzalo Sánchez-Molero, "Mateo Vázquez, un secretario entre libros".

${ }^{27}$ Ernesto Lucero, "Bueyes y Pensé Que en la Filosofía cortesana de Alonso de Barros", Congreso Internacional "Entre historia y ficción: formas de la narrativa áurea", Universidad de Jaén, 6-7 de noviembre de 2018. 
amplia del patrón castellanista, esta sí, plural, colectiva, conjunta, coordinada. Es el momento de abordarlo.

El vínculo del secretario con Alonso de Barros debe de venir de antiguo, aunque nos movemos por ahora en el terreno de las hipótesis. Puede haber motivado que se conozcan algún contacto esporádico en el ámbito de la cultura o el oficio de aposentador de Barros u otras cuestiones profesionales. José Martínez Millán se refiere a Barros como escribano de Vázquez. La letra del segoviano y los oficios que solicita invitan a pensar que tiene algunos estudios. Entre los documentos que atesora Mateo Vázquez en los «Diversos de curiosidad», esos papeles que no cumplen necesariamente una función política, se acomoda el «Discurso y difinición del privado», que debe de escribir Barros por estas fechas y que aporta otros indicios de su relación. Se trata de una paráfrasis del capítulo 8 de la Ética a Nicómaco de Aristóteles, en que equipara la amistad con la privanza:

Yo pienso que es casi una misma cosa la privanza que alcanza el menor con el mayor que el amistad que se traba entre los iguales, porque todo nace de una misma fuente o satisfación que el uno concibe del otro, de que le será a propósito aquella compañía para algún fin ${ }^{28}$.

Aun con los pocos datos de que disponemos no parece extraña la incorporación de Alonso de Barros en el plan de Mateo Vázquez. En este marco, se puede concebir el proceso editorial de su ópera prima como uno más de los frutos de la polémica alrededor de su ascendencia, puesta en tela de juicio por sus rivales. De hecho, solo unos pocos títulos unen el escudo a una dedicatoria lo suficientemente aduladora. Poner el escudo en portada - advierte R. de la Flor a propósito de Lerma- supone intentar imponer los valores genealógicos sobre cualesquiera otros valores que se promuevan en el libro, incluso si se trata de un prontuario de cortesanía como el que nos ocupa ${ }^{29}$, lo que supone un giro notable en la trayectoria del patrón castellanista, paradigma del ascenso de los letrados al gobierno de la Monarquía.

La Filosofía cortesana es la última obra que porta el escudo de Mateo Vázquez de la que tenemos noticia pero, antes de ceñirnos a su estudio, vamos a repasar los otros dos casos de su publicación en la portada de un libro, sin perder de vista que su misma confección corre pareja con estas apariciones ${ }^{30}$. El diseño se utilizará, en

\footnotetext{
${ }^{28}$ IVDJ, envío 29, caja 42, fol. 175 r.

${ }^{29}$ Ver Fernando Rodríguez de la Flor, "Las esferas del poder: emblemática y nueva ética cortesana entre 1599-1610", De Re Publica Hispaniae: una vindicación de la cultura política en los reinos ibéricos en la primera modernidad, ed. Francisco José Aranda Pérez, José Damiâo Rodrigues (Madrid: Sílex, 2008), 334-335.

${ }^{30}$ Díaz Gito ("Encomio”) refiere el proceso de preparación del escudo a propósito de la redacción propagandística de la Corsica de Calvete de Estrella, que tiene lugar en esas fechas y que permite establecer una fecha ad quem para su gestación, aunque a la vista de alguna muestra de 1583, estaba prácticamente perfilado desde entonces. Sobre la creación del escudo no podemos evitar que nos vengan a la memoria las palabras de Godoy en el Diálogo de los pajes: «Por mejor hidalgo se tienen, en opinión de todos, el de la propiedad quel de sola posesión, y el del solar conosçido quel que no le
} 
primer lugar, en el tratado de quien fuera su maestro en la universidad, el médico y helenista Fernando Valdés: De utilitate Venae sectionis in Variolis, ac aliis affectibus puerorum, con su aparente traducción: Tratado de la utilidad de la sangría en las viruelas y otras enfermedades de los muchachos (Sevilla: Fernando Díaz, 1583); y, más tarde, en Comparaciones o similes para los vicios y virtudes (Alcalá de Henares: Pérez Ramírez, 1586) de Juan Pérez de Moya, un listado admonitorio de comparaciones apropiadas para adornar sermones, que se presenta como «muy útil y necessario para predicadores y otras personas curiosası ${ }^{31}$.

El libro de Valdés está catalogado como volumen facticio en la Biblioteca Nacional ${ }^{32}$ y solo hemos hallado referencias a él que lo consideran dos libros distintos. Aunque el ejemplar tiene, en efecto, dos principios con el grabado y dos dedicatorias, solo presenta unos documentos administrativos conjuntos, por lo que podemos aseverar que consiste en una sola obra en dos lenguas. Se diría que primero se compuso el tratado en latín, como corresponde a la materia, y que después se aplicó el autor a sintetizar en castellano las ideas esenciales, con remisiones a la versión primera, para que todos la puedan entender. El propio autor declara que «va escrita en lengua latina para los que la saben, y también en romance para los demás». El lector

por la una o por la otra [...] descubrirá la verdad, que es la que yo aquí solamente pretendo aclarar para el común aprovechamiento del pueblo, sin ninguna vanidad ni demostración de ingenio. La de romance, que va primero, es como suma o recopilación de la del latín. Y así la va refiriendo siempre, y en muchas cosas del todo remitiéndose a ella. Porque allí va todo tratado largamente con muchas autoridades y razones. (Fols. 5r-v)

Pero sospechamos que lo que de verdad ha de comprenderse para cumplir el propósito de Valdés y, desde luego, contar con el beneplácito de Mateo Vázquez es la dedicatoria, cuatro veces más larga que la que figura en la parte latina y que trasluce un servilismo obsequioso que raya en los límites del decoro para quien espere encontrar las palabras de un maestro a su discípulo ${ }^{33}$. El libro va en cuarto y lleva un

tiene y que, cuando viene a sacar su executoria, ha menester inventar armas que poner en ella [...]» (Coloquio segundo, capítulo 4, 38). En esas estuvo la camarilla de Vázquez (Díaz Gito, "Encomio") y para esa tarea había comprado ya con anterioridad algunos libros que versaban sobre ciertos elementos que iba a introducir en el blasón familiar (Gonzalo Sánchez-Molero, La Epístola, 294).

${ }^{31}$ Pérez de Moya, Comparaciones o similes para los vicios y virtudes, ed. de Consolación Baranda (Madrid: Fundación José Antonio de Castro, 1996), 1.

${ }^{32} \mathrm{El}$ volumen lleva la signatura $\mathrm{R} / 5735$.

${ }_{33}$ Después de la invocación, podemos leer en la dedicatoria la exposición de la más remota y peregrina genealogía del secretario. Este es sin duda la fuente última del texto que recoge Fernando Valdés, que resulta casi idéntico al tenor del que aparece en el volumen de Argote de Molina, Nobleza del Andalucía (Sevilla: Fernando Díaz, 1588), ed. de Manuel Muñoz y Garnica (Jaén: Francisco López Vizcaíno, 1876), 520-522. Los libros, totalmente instrumentalizados, amplifican la imagen autopromocional que Mateo Vázquez deseaba proyectar de su grandeza. También resulta muy semejante el texto que figura en la copia del linaje que maneja el marqués de Cerralbo en su trabajo pionero, donde se recoge la relación enviada por Mateo Vázquez a un corresponsal desconocido, en la 
grabado en sus dos principios - castellano y latino- que muestra las armas del secretario en un bosquejo ya muy definido dentro del proceso de su composición. Entre esta configuración y los blasones que constan en las ediciones de los otros dos títulos, apenas se detecta otra diferencia que la fisonomía o el cabello del ángel del timbre del escudo y la cruz que sostiene, que sustituye el lábaro original de la familia Lecca. Esta xilografía parece de mayor calidad que las demás ${ }^{34}$ y es la única que

que no solo le corrige una equivocación con su apellido —emplea «Leuca», en lugar de «Lecca»— sino que aprovecha la ocasión para endilgarle un papel con su más que improbable ascendencia imperial. Valga por todos, a modo de ejemplo, el texto de Valdés, tal y como aparece en la dedicatoria del libro al que nos estamos refiriendo: «Cuán excelente y real profesión sea la de la medicina, merced inestimable dada por favor del cielo a los hombres para la conservación de su salud, enséñanlo muchos ejemplos de grandes príncipes y reyes, que no solamente la honraron sino también se honraron en favorecerla [...] No parece ajena ni indigna del favor de VM antes como persona de tan ilustre sangre, y que entre los títulos de sus pasados puede contar blasones y dictados de príncipes y señores, le es muy proprio autorizarla, y recebir en su protección y amparo los que la profesan. Muy sabida cosa es y muy cierta la grandeza y antigüedad de la casa de Lecca, pues como es notorio, procede y desciende de los verdaderos emperadores de Constantinopla y es como seminario de las más nobles familias en la isla de Córcega y en otras naciones y provincias, como es en Roma y en Italia la casa Colonna, cuya grandeza es conocida en toda Europa, no habiendo historia de casi setecientos años a esta parte que no refiera gran valor de pontífices y cardenales desta esclarecida familia, contando hechos señalados de grandes señores y capitanes que della han procedido. Desta ilustrísima casa fue aquel gran Hugo Colonna, que por su valor vino a ser señor de Córcega, del cual procedió el conde Juan Paulo de Lecca, sucesor en el mesmo estado. En cuya posteridad se conservará hasta hoy la sucesión si las reñidas competencias de pisanos y genoveses no fueran causa que se enajenase de sus legítimos poseedores. Fue este ilustrísimo conde más aína acrecentador que fundador de la ilustrísima casa de Lecca pues, como está dicho, desciende de los emperadores de Constantinopla. Desta cabeza por línea derecha viene VM abrazando juntamente por ambas líneas las nobilísimas cualidades destas casas, como es muy público y notorio en Córcega y en estos reinos muy recebido y averiguado por antiquísimos y gravísimos testimonios de irrefragable verdad, como se ha bien hecho la prueba en algunas honrosísimas ocasiones, especialmente habiendo VM alcanzado el lugar y la aceptación que tiene cerca del mayor rey que jamás ha habido con oficio de su consiliario y secretario y de la Sancta General Inquisición. La cual, por tan inviolable e indispensable estatuto, no admite aun para ministros humildes a quien no es de muy limpio y [a]cendrado linaje sin liga de ruin metal. El cual solo argumento es bastantísimo para fundar esta verdad tan notoria de la limpieza del claro linaje de VM cuando no hubiera los sobredichos, que son tan ciertos y averiguados. Por estos mesmos la ciudad de Sevilla deseando honrar su república con tan principal caballero y vecino suyo, con gran conformidad de todo el cabildo declaró ser VM caballero hijodalgo y como a tal se le guardasen sus franquezas y privilegios, que gozan los caballeros hijosdalgo que moran en la misma ciudad. Por estas razones y la que yo tengo de tan antiguo servidor, confiado en el noble y cortés acogimiento que VM hace a semejantes estudios, me atreví a dedicarle este tratado de más provecho que volumen, y una breve suma dello en romance para que en alguna manera se comunique generalmente a todos [...] De Sevilla a primero de noviembre. 1583».

34 La calidad de la imagen no alcanza pero recuerda la del escudo del cardenal Diego de Espinosa con que el destacado orfebre Juan de Arfe encabezó su Quilatador de la plata, oro y piedras (Valladolid: Alonso y Diego Fernández de Córdoba, 1572), que sin duda conoció Vázquez de Lecca y pudo llevarlo a emular a su antecesor en la construcción de su imagen desde las planchas. Véase Elena Páez Ríos, Repertorio de grabados españoles en la Biblioteca Nacional (Madrid: Imprenta del Ministerio de Cultura, 1981), 61. En 1588, Argote de Molina describe detenidamente las armas de la familia Lecca, haciendo alusión al secretario, para quien trabaja, en su Nobleza del Andalucía, 521: «Sus armas son un escudo de cuatro cuarteles, el primero y último rojos, y los otros dos verdes; y en medio del escudo un castillo, y 
comparece en la edición príncipe. Resulta lógico, en cualquier caso, que el erudito se aproxime al alumno al que la fortuna ha favorecido de manera tan notable en busca de su amparo y de su «generoso natural»:

\begin{abstract}
A VM suplico lo admita en su favor y gracia asegurándolo con la autoridad de su nombre de cualquier adversario y acordándose cuánto he profesado servirle dende el tiempo de mi profesión en la insigne universidad de Alcalá de Henares, donde VM me honró algunas veces en oírme, siendo testigo y buena parte de la aprobación y aplauso público con que yo leía y disputaba. Dende entonces descubrí en aquellos juveniles años de su edad, una gentileza y claridad de ingenio admirable, un generoso natural levantado a cosas grandes con ciertos vislumbres y muestras del resplandor presente y del estado en que, por lo que valen tan excelentes virtudes y partes, está constituido. En el cual, como Dios tiene puesto a VM para que emplee todo lo que puede en favor y amparo de la virtud y letras, así los que las profesan tienen obligación de rogar a Dios le conserve en él muy largos y dichosos tiempos con el acrecentamiento que se merece.
\end{abstract}

Ya hemos comentado el hecho de que el escudo aparezca solo en la segunda edición de la Filosofía cortesana. Sucede otro tanto en la obra de Pérez de Moya ${ }^{35}$. Sabemos que, aunque se concedió licencia en 1581 para la impresión de las Comparaciones o similes para los vicios y virtudes no se publica por primera vez hasta 1584 (Alcalá de Henares: Juan Gracián). La portada lleva entonces una entalladura que dibuja una marca con una cruz bajo el lema INRI, con calavera a sus pies, quedando en segundo plano una iglesia ${ }^{36}$. Esta misma disposición se halla en alguna obra impresa con la marca Pere Malo en 1588 y en un emblema de Villava ${ }^{37}$.

La cruz que porta el ángel en la portada de las Comparaciones o símiles es lobulada, pero de nuevo recta en la Filosofía cortesana, como en la del tratado médico de Valdés. En la portada del libro de Barros todo el diseño se encierra en un óvalo con la divisa «In hoc signo vinces», variante mínima de la original de la familia Lecca, que circunscribe también el reverso de la medalla que mandó grabar con su efigie Mateo Vázquez $^{38}$, y que constituye un rasgo diferencial con respecto a las otras imágenes. Si

en lo alto dél, una águila imperial de dos cabezas, con coronas reales; y debajo del castillo un león rampante. Y por orla, en campo de oro, cinco escudos rojos, y en cada uno una columna de plata con una corona real de oro [...] y por timbre, un ángel con el lábaro y con la letra In hoc signo victor eris, usada de los emperadores de Constantinopla». Resulta particular que el linaje que nos ocupa debería haber sido estudiado en la segunda parte, que nunca se publicó, donde pensaba tratar de los reinos de Granada y Sevilla, mientras que esta primera versa sobre Jaén y Córdoba. Argote de Molina encarece la capacidad de trabajo de su patrón: «que parece exceder a fuerzas humanas» (Ibídem, 521).

${ }^{35}$ Será también el caso del Vocabulario de las dos lenguas toscana y española de Cristóbal de las Casas, (Sevilla: Andrea Pescioni, 1583), del que trataremos más abajo.

36 Véase Julián Martín Abad, La imprenta en Alcalá de Henares (1502-1600) (Madrid: Arco/Libros, 1991), 1097, núm. 955. Este bibliógrafo la describe así: «Grab. xil. representando una cruz coronada de espinas, delante de dos edificaciones, dentro de una cartela circular con adornos exteriores».

${ }^{37}$ Ver Antonio Bernat Vistarini y John Cull, Enciclopedia de emblemas españoles ilustrados (Madrid: Akal, 1999), núm. 496; véase también núms. 2.173 y 2.174 de Francisco Vindel, Manual gráfico descriptivo del bibliófilo hispanoamericano (Madrid: Góngora, 1931), vol. VII.

${ }_{38}$ El Museo Arqueológico Nacional conserva dos medallas iguales de Mateo Vázquez: Inventario 1993/80/434-1. Bronce; 53 mm; 60,83 g.; e Inventario 1993/80/434-2. Bronce; 52,80 mm; 60,69 g. Con anilla. Álvarez-Ossorio, que llevó a cabo la catalogación, data las piezas antes de su 
tenemos en cuenta que el desarrollo del escudo había concluido hacia finales de 1585, según ha estudiado con detenimiento Manuel Díaz Gito a propósito del cruce epistolar que tiene lugar entre el secretario y Calvete de Estrella para la confección de su Corsica, quizá el óvalo se incorporara como uno de los últimos elementos a la figuración, ya muy avanzada a la altura de 1583.

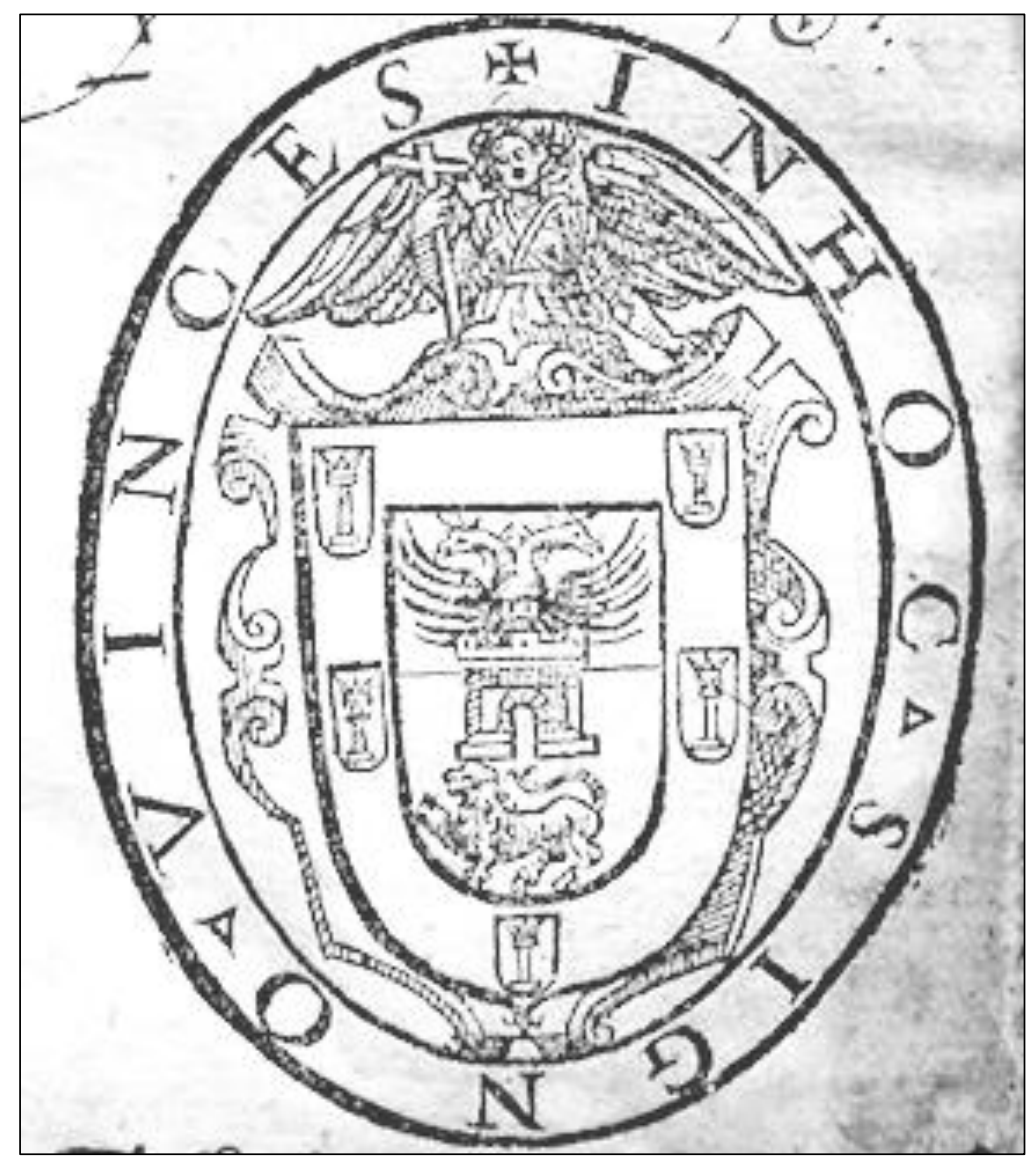

Figura 1: Escudo en la edición de Pedro Madrigal de la Filosofía cortesana

nombramiento como secretario del rey, puesto que no consta, a diferencia de lo que sucede con los cargos de Antonio Pérez o Espinosa, escritos en sendas medallas conmemorativas. Véase Felipe II: un monarca y su época. Las tierras y los hombres del rey, (Valladolid: Museo Nacional de Escultura y Madrid: Sociedad estatal..., 1998), 300 y ss. Sin embargo, la composición del escudo debe de ser posterior a diciembre de 1585, según la información que ha reunido Díaz Gito ("Encomio", 88) y, muy probablemente, de fechas próximas al texto de Barros, por la semejanza de las figuras. En este sentido, conviene revisar las apreciaciones del historiador, ya que no formulaba ninguna hipótesis de autoría porque la técnica de grabación no correspondía a esos años. Debió de tratarse de un grabador de calidad. Quizá no Jacopo Trezzo, pero pudiera haber sido uno de los discípulos de Abondio o Leone Leoni. 
Estos tres libros destacan dentro de una estrategia global de Mateo Vázquez, que sobrepasa la acotación heráldica, con ser muy importante, al difundir el flamante blasón. Pero, en verdad, el conjunto de estas y otras dedicatorias proyecta una imagen pública del sevillano como hombre virtuoso y trabajador infatigable, además de satisfacer la necesidad de simular que se sigue gozando del favor regio, como preconizaban algunos tratadistas, cuando su posición dista de los mejores momentos de privanza ${ }^{39}$.

Los últimos atisbos de esta actividad propagandística que hemos registrado son la carta que contiene el inaugural artículo del marqués de Cerralbo y la dedicatoria que le ofrece Simón Abril en la traducción de las Epistolas familiares de Cicerón ${ }^{40}$. El brillante humanista efectúa en ese lugar, tras una loa del secretario y de su oficio y cortesanía, una reflexión sobre la importancia de brindar los textos en romance para su conocimiento general ${ }^{41}$. La importancia de la traducción y del castellano hacen acto de presencia de nuevo en los alrededores del secretario ${ }^{42}$. Valdés ofrece una versión sumaria en romance de su polémica en favor de las sangrías y en romance llevan su letra los emblemas de las casas de la Filosofía cortesana. No será la última vez que esta preocupación por la lengua vernácula aparezca en las páginas de este estudio ni tampoco en la vida de Alonso de Barros cuando Mateo Vázquez ya no esté, como se deja sentir en los elogios que en los Proverbios morales y en las Emblemas moralizadas se dedican de manera recíproca desde los paratextos el contador Hernando de Soto y él a finales de siglo ${ }^{43}$.

Después de estas dos ediciones madrileñas de la Filosofía cortesana, el libro no se publicará más en Castilla. La tercera edición surgirá de un taller napolitano regentado por Giuseppe Cacchii. En ella, se reproducen los mismos documentos legales que ya contenían sus antecesoras. Sin descartar, por ello, los motivos legales que suelen acompañar la salida de las obras a otras prensas, queremos apuntar algunas otras razones. La primera salta a la vista de quien pueda contemplar el bellísimo tablero que acompaña a la edición —el único que conservamos ${ }^{44}$ - y, este

39 Antonio Álvarez-Ossorio, "Proteo en palacio: el arte de la disimulación y la simulación del cortesano", en El Madrid de Velázquez. y Calderón. Villa y Corte en el siglo XVII, ed. Miguel Morán y Bernardo García, tomo I (Madrid: Akal, 2000), 128. Probablemente la culminación de la confección de una biblioteca nobiliaria se halle en el mismo camino. Ver Gonzalo Sánchez-Molero, La Epistola; "La biblioteca".

${ }^{40}$ Los deciséis libros de la epístolas o cartas de M. Tulio Cicerón, vulgarmente llamadas familiares: traduzidas de la lengua latina en castellana por el Doctor Pedro Simón Abril (Madrid: Pedro Madrigal, 1589). Este libro se halla en el inventario de la biblioteca de Alonso de Barros. Ver Trevor J. Dadson, "La biblioteca de Alonso de Barros, autor de los Proverbios morales”, Bulletin Hispanique 89, (1987): 27-53, núm. 115.

${ }^{41}$ Ibídem, fols. $5 \mathrm{r}-8 \mathrm{v}$.

42 Esta preocupación didáctica que afecta al empleo del castellano como lengua vehicular en algunas de las obras que venimos citando aquí, parece encajar con las necesidades del perfil de Mateo Vázquez.

43 Alonso de Barros, Proverbios morales (Madrid: Luis Sánchez, 1598); Hernando de Soto, Emblemas moralizadas, ed. de José Julio García Arranz y Nieves Pena Sueiro (Madrid: José J. de Olañeta, 2017).

${ }^{44}$ Hemos postulado la hipótesis de que las ediciones madrileñas debieron de contar con sus respectivas pinturas, que no pudieron ser la misma, en "El tablero de juego de 1588 en las ediciones madrileñas de la Filosofía cortesana de Alonso de Barros", Romance Notes 59 (2019), de próxima aparición. 
sí, con privilegio propio para el reino de Nápoles, y firmado por Mario Cartaro en $1588^{45}$. Sabemos que los emblematistas españoles se quejaban de la rudeza de los entalladores de Castilla, el mismo Hernando de Soto, por ejemplo. Los grabadores italianos, en cambio, eran muy reputados, no solo por su habilidad, sino por el sabio uso del aguafuerte, que permitía mayor precisión y sutileza. Tampoco está de más recordar los orígenes italianos del juego de la oca en que se basa la Filosofía cortesana, cuya adaptación hemos analizado en profundidad en otro lugar. Sin embargo, creemos que no se agotan las conexiones con Italia en estos pocos aspectos que acabamos de mencionar. Falta un argumento: Mateo Vázquez.

Como explica Gonzalo Sánchez Molero ${ }^{46}$, «tras lograr la defenestración política de Antonio Pérez, Vázquez incrementó su interés por todo lo relacionado con Italia, que fue parejo con su renovada preocupación por despejar cualquier duda acerca de su ascendencia». El mismo historiador da idea de la controversia que alborotaba también Italia sobre la cuestión genealógica del secretario al transcribir una carta de septiembre de 1582 del agente de Mateo Vázquez, Bartolomé de Quesada, quien, refiriéndose a «una memoria del origen de su nobleza» - la información sobre su linaje que se estaba realizando- «se mostró entusiasmado con una obra que pondría en su sitio a los bellacos que dudaban del honor del secretario». Dos años más tarde difunde la versión completa entre los cardenales romanos ${ }^{47}$. De hecho, la primera epístola que dirige a Ascanio Colonna data de junio de 1583 y desde esas fechas firma como Mateo Vázquez de Lecca y Colonna ${ }^{48}$.

A mayor abundamiento, Escobar ha explorado, por su parte, las conexiones entre Sevilla, Alcalá de Henares e Italia, que implican al secretario ${ }^{49}$. En ese contexto cobra sentido la dedicatoria a la segunda edición del Vocabulario de las dos lenguas toscana y española de Cristóbal de las Casas, impresa por Pescioni en 1583, y dirigida a Mateo Vázquez, libro que constituye un índice más de su vínculo con Italia. La cuestión requiere algún comentario aparte de los que apunta el investigador, pues solicita la licencia el mercader de libros Diego Núñez, no el autor, como es obvio, pues había fallecido en 1576; y si no él, debió de ser algún miembro de su círculo de humanistas. Eso explica que aunque en la portada se ofrece la obra al secretario, no figure en el interior nota dedicatoria alguna. El propio Escobar sigue el hilo de esas conexiones en otra dedicatoria, la de Jerónimo de Carranza en sus Cinco libros sobre la ley de injuria, donde se declara «particular servidor» del secretario e inicia la consabida

\footnotetext{
${ }^{45} \mathrm{La}$ licencia de impresión de la Filosofía cortesana no se refiere exclusivamente a Castilla, sino a todos los reinos y señoríos de su Majestad. Esta edición de 1588 cuenta, como decimos, con los mismos documentos legales que las precedentes mientras que la pintura que la acompaña declara depender de un privilegio de Alonso de Barros para el «Regno di Napoli». A pesar de ello, pensamos que los cambios y supresiones en el texto de la obra no se deben a indicaciones concretas del autor, sino a decisiones del taller.

46 Gonzalo Sánchez-Molero, "La biblioteca”, 291.

47 Ibídem, 292.

48 Marín Cepeda, Cervantes, 327.

49 Francisco Javier Escobar, "Humanismo y espiritualidad en tiempos de Felipe II: posicionamiento profesional de Mal Lara, un cartapacio de Mateo Vázquez y Cervantes a los diecinueve años”, eHumanista 35 (2017): 62.
} 
alabanza genealógica remontándose a Paulo de Lecca, pero, curiosamente, sin enlazar este linaje con la familia Colonna ${ }^{50}$.

Queda mucho por saber, pero es hora de recapitular. Hemos demostrado que Alonso de Barros logra gracias a su vínculo con Mateo Vázquez un codiciado oficio real compatible con su cargo de aposentador. Uno de sus últimos servicios antes de conseguirlo, y no el menor, consiste en la publicación de un pequeño manual de cortesanía, la Filosofía cortesana. Tras una primera edición dedicada al secretario, se publica en pocos meses una segunda donde la incorporación del escudo de Mateo Vázquez contribuye a la campaña promocional de su rancio abolengo, en la que habían participado otros autores desde comienzos de la década de 1580. Paradójicamente, el escudo avala unos valores propios de la nobleza de sangre, que contradicen la exaltación del trabajo promovida desde el tablero de juego, característica de los letrados castellanistas y, en particular, de nuestro secretario, en un intento de adaptarse a los nuevos vientos que soplan en la Corte. El cambio de editor o la intervención de algunos personajes en la segunda edición cobran un nuevo sentido, por consiguiente, en el propósito de Mateo Vázquez de injertarse en el árbol genealógico de una notable familia romano-napolitana, que ilumina también de una manera natural el lugar de la afortunada edición de 1588, que ha permitido conocer el tablero grabado por Mario Cartaro de este curioso juego de mesa.

${ }^{50}$ Francisco Javier Escobar, "Dos textos desconocidos de Jerónimo de Carranza a propósito del XI Conde de Niebla y Mateo Vázquez (con unas notas sobre Hernando de Vega)", El duque de Medina Sidonia: mecenazgo y renovación estética (Huelva: Universidad de Huelva, 2015), 139-141. 


\section{REFERENCIAS BIBLIOGRÁFICAS}

Álvarez-Ossorio, Antonio, "Proteo en palacio: el arte de la disimulación y la simulación del cortesano", en El Madrid de Velárquezy Calderón. Villa y Corte en el siglo XVII, ed. Miguel Morán y Bernardo García, tomo I, (Madrid: Akal, 2000), 111-137.

Argote de Molina, Gonzalo, Nobleza del Andalucía (Sevilla: Fernando Díaz, 1588).

Barros, Alonso de, Filosofía cortesana, ed. Trevor J. Dadson (Madrid: Comunidad de Madrid, 1987), 3 vols.

—, Proverbios morales (Madrid: Luis Sánchez, 1598).

Bernat Vistarini y John Cull, Enciclopedia de emblemas españoles ilustrados (Madrid: Akal, 1999).

Cavillac, Michel, "Libros, lecturas e ideario de Alonso de Barros, prologuista de Guzmán de Alfarache (1599)", Bulletin Hispanique 100 (1998): 69-94.

Cabello Núñez, José, "Nuevos documentos para la biografía de Miguel de Cervantes Saavedra, un comisario real de abastos en los antiguos Reinos de Jaén y Sevilla (1592-1593)", Anales cervantinos 48 (2016): 13-51. doi: 10.3989 /anacervantinos.2016.001

Clemente San Román, Yolanda, Tipobibliografía Madrileña. La imprenta en Madrid en el s. XVI (1566-1600) (Kassel: Reichenberger, 1998), 3 vols.

Dadson, Trevor J., "La biblioteca de Alonso de Barros, autor de los Proverbios morales", Bulletin Hispanique 89 (1987): 27-53.

Delgado Casado, Juan, Diccionario de impresores españoles (siglos XV-XVII) (Madrid: Arco/Libros, 1996).

Díaz Gito, Manuel, "Una carta en torno al escudo de armas de Mateo Vázquez de Leca en la Corsica de Calvete de Estrella", Calamus renascens 10 (2009): 53-70.

-, "Encomio de Mateo Vázquez y heráldica de los Lecca en la 'Corsica' de Calvete de Estrella", Talía dixit. Revista Interdisciplinar de Retórica e Historiografía 9 (2014): 73-95.

Escobar, Francisco Javier, "Dos textos desconocidos de Jerónimo de Carranza a propósito del XI Conde de Niebla y Mateo Vázquez (con unas notas sobre Hernando de Vega)", El duque de Medina Sidonia:mecenazgo y renovación 
estética, ed. José Manuel Rico García, Pedro Ruiz Pérez (Huelva: Universidad de Huelva, 2015), 119-142.

-, "Humanismo y espiritualidad en tiempos de Felipe II: posicionamiento profesional de Mal Lara, un cartapacio de Mateo Vázquez y Cervantes a los diecinueve años", eHumanista 35 (2017): 16-78.

Felipe II: un monarca y su época. Las tierras y los hombres del rey (Madrid: Sociedad estatal para la conmemoración de los centenarios de Carlos V y Felipe II, 1998).

Gonzalo Sánchez-Molero, José Luis, "Mateo Vázquez de Leca, un secretario entre libros", Hispania 65, n²21 (2005): 813-846.

-, La "Epistola a Mateo Vázquez": bistoria de una polémica literaria en torno a Cervantes (Alcalá de Henares: Centro de Estudios Cervantinos, 2010).

- "Mateo Vázquez de Leca, un secretario entre libros, 2, La biblioteca", Hispania Sacra 66, nº1 (2014): 279-321. doi: 10.3989/hs.2014.070.

Hermosilla Diego de, Diálogo de los pajes, ed. José Manuel Franco Rodríguez (Almería: Universidad de Almería, 2003).

Lovett, Albert. W., Philip II and Mateo Vázquez. de Leca: the Government of Spain (15721592) (Genêve: Librairie Droz, 1977).

Lucero, Ernesto, "Las ediciones antiguas de la Filosofía cortesana de Alonso de Barros. Una historia del texto", Criticón 127 (2016): 169-195.

-, "El tablero de juego de 1588 en las ediciones madrileñas de la Filosofía cortesana de Alonso de Barros", Romance Notes 59 (2019): en prensa.

-, "Unas palabras sobre el ocio cortesano: La Filosofía cortesana y el juego de la oca", ponencia en el Simposio Internacional sobre Caballería y Corte (SICC), (Jaén: Universidad de Jaén, 30 de enero de 2018, pendiente de publicación).

-, "Bueyes y Pensé Que en la Filosofía cortesana de Alonso de Barros", comunicación en el Congreso Internacional "Entre historia y ficción: formas de la narrativa áurea" (Jaén: Universidad de Jaén, 6-7 de noviembre de 2018, pendiente de publicación).

Marín Cepeda, Patricia, Cervantes y la corte de Felipe II. Escritores en el entorno de Ascanio Colonna (1560-1608) (Madrid: Polifemo, 2015). 
Marqués de Cerralbo, "El secretario Mateo Vázquez y la genealogía", Revista Hidalguía 3 (1953): 621-628.

Martín Abad, Julián, La imprenta en Alcalá de Henares (1502-1600) (Madrid: Arco/Libros, 1991).

Martínez Millán, José, “Filosofía cortesana de Alonso de Barros (1587)”, en Política, religión e inquisición en la España moderna: Homenaje a Joaquín Pérez Villanueva, ed. P. Fernández Albaladejo, J. Martínez Millán y V. Pinto Crespo (Madrid: Universidad Autónoma de Madrid, 1996), 461-482.

- «Cervantes y las facciones cortesanas de su tiempo (1547-1616)», Colecciones cervantinas (Madrid: Ministerio de Educación, Cultura y Deporte, Subdirección General de Documentación y Publicaciones, 2016), 86-104.

Morreale, Margherita, "Estudio preliminar" a Lucas Gracián Dantisco, Galateo español (Madrid: CSIC, 1968).

Páez Ríos, Elena, Repertorio de grabados españoles en la Biblioteca Nacional, (Madrid: Imprenta del Ministerio de Cultura, 1981).

Pérez de Moya, Juan, Comparaciones o similes para los vicios y virtudes. Philosophia secreta, ed. de Consolación Baranda (Madrid: Fundación José Antonio de Castro, 1996).

Pérez Pastor, Cristóbal, Bibliografía madrileña o Descripción de las obras impresas en Madrid, I-III (Madrid: Tip. de los Huérfanos [1] y Tip. de la Revista de Archivos, Bibliotecas y Museos [II-III], 1891-1907) [Eds. facs.: Amsterdam: Gérard Th. Van Heusden, 1970; Pamplona: Analecta, 2000].

Riba García, Carlos, Correspondencia privada de Felipe II con su secretario Mateo Vázquez, 1567-1591 (Madrid: CSIC, 1959).

Rivero, Casto María del, El Ingenio de la moneda de Segovia (Madrid: Maxtor, 1919).

Rodríguez de la Flor, Fernando, "Las esferas del poder: emblemática y nueva ética cortesana entre 1599-1610", De Re Publica Hispaniae: una vindicación de la cultura política en los reinos ibéricos en la primera modernidad, ed. Francisco José Aranda Pérez, José Damiâo Rodrigues (Madrid: Sílex, 2008), 321-348.

Sanz Ayán, Carmen, Ponencia plenaria que ofreció en el congreso de AISO titulada "Linajes de papel. La imagen de la nueva nobleza en los paratextos del siglo de oro" (Madrid: Universidad Complutense, julio de 2017, pendiente de publicación). 
Simón Abril, Pedro, Los deciséis libros de la epistolas o cartas de M. Tulio Cicerón, vulgarmente llamadas familiares: traduz̨idas de la lengua latina en castellana por el doctor Pedro Simón Abril (Madrid: Pedro Madrigal, 1589).

Soto, Hernando de, Emblemas moralizadas, ed. de José Julio García Arranz y Nieves Pena Sueiro (Madrid: José J. de Olañeta, 2017).

Suárez de Figueroa, Cristóbal, Plaza universal de todas ciencias y artes (Madrid: Luis Sánchez, 1615). Copia digital (Valladolid: Junta de Castilla y León. Consejería de Cultura y Turismo, 2009-2010, https://bibliotecadigital.jcyl.es/es/consulta/registro.cmd?id=4774, consultado el 27 de septiembre de 2017).

Valdés, Fernando de, Tratado de la vtilidad de la sangría en las Viruelas y otras enfermedades de los Muchachos (Sevilla: en casa de Fernando Díaz, 1583).

Vindel, Francisco, Manual gráfico descriptivo del bibliófilo bispanoamericano (Madrid: Góngora, 1931).

Recibido: 11 de marzo de 2019

Aprobado: 15 de abril de 2019 